2009s-22

\title{
The Robustness of Economic Activity to Destructive Events
}

\author{
John W. Galbraith
}

Série Scientifique
Scientific Series

Montréal
Mai 2009

(C) 2009 John W. Galtraith. Tous droits réservés. All rights reserved. Reproduction partielle permise avec citation du document source, incluant la notice $\odot$.

Short sections may be quoted without explicit permission, if full credit, including $\odot$ notice, is given to the source.
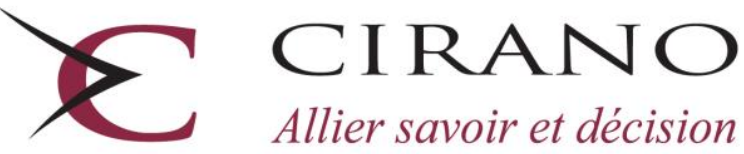

Allier savoir et décision

Centre interuniversitaire de recherche en analyse des organisations 


\section{CIRANO}

Le CIRANO est un organisme sans but lucratif constitué en vertu de la Loi des compagnies du Québec. Le financement de son infrastructure et de ses activités de recherche provient des cotisations de ses organisations-membres, d'une subvention d'infrastructure du Ministère du Développement économique et régional et de la Recherche, de même que des subventions et mandats obtenus par ses équipes de recherche.

CIRANO is a private non-profit organization incorporated under the Québec Companies Act. Its infrastructure and research activities are funded through fees paid by member organizations, an infrastructure grant from the Ministère du Développement économique et régional et de la Recherche, and grants and research mandates obtained by its research teams.

\section{Les partenaires du CIRANO}

Partenaire majeur

Ministère du Développement économique, de l'Innovation et de l'Exportation

\section{Partenaires corporatifs}

Banque de développement du Canada

Banque du Canada

Banque Laurentienne du Canada

Banque Nationale du Canada

Banque Royale du Canada

Banque Scotia

Bell Canada

BMO Groupe financier

Caisse de dépôt et placement du Québec

DMR

Fédération des caisses Desjardins du Québec

Gaz de France

Gaz Métro

Hydro-Québec

Industrie Canada

Investissements PSP

Ministère des Finances du Québec

Power Corporation du Canada

Raymond Chabot Grant Thornton

Rio Tinto Alcan

State Street Global Advisors

Transat A.T.

Ville de Montréal

\section{Partenaires universitaires}

École Polytechnique de Montréal

HEC Montréal

McGill University

Université Concordia

Université de Montréal

Université de Sherbrooke

Université du Québec

Université du Québec à Montréal

Université Laval

Le CIRANO collabore avec de nombreux centres et chaires de recherche universitaires dont on peut consulter la liste sur son site web.

Les cahiers de la série scientifique (CS) visent à rendre accessibles des résultats de recherche effectuée au CIRANO afin de susciter échanges et commentaires. Ces cahiers sont écrits dans le style des publications scientifiques. Les idées et les opinions émises sont sous l'unique responsabilité des auteurs et ne représentent pas nécessairement les positions du CIRANO ou de ses partenaires.

This paper presents research carried out at CIRANO and aims at encouraging discussion and comment. The observations and viewpoints expressed are the sole responsibility of the authors. They do not necessarily represent positions of CIRANO or its partners. 


\title{
The Robustness of Economic Activity to Destructive Events
}

\author{
John W. Galbraith ${ }^{\dagger}$
}

\begin{abstract}
Résumé / Abstract
L'efficacité des accords économiques constitue le centre d'intérêt de la recherche en économie, mais on peut se demander si les améliorations observées en matière d'efficacité au sein des économies développées ont été accompagnées d'une vulnérabilité accrue de la production aux événements catastrophiques. Pour répondre à cette question de façon utile, nous avons besoin d'outils pouvant être mis en œuvre dans le but de mesurer la vulnérabilité de la production aux perturbations ou aux bouleversements.

La présente étude tente de mettre en place des mesures rudimentaires de cette vulnérabilité potentielle accrue au sein des systèmes économiques. Pour ce faire, nous nous appuyons sur les concepts issus de la théorie de l'information, sur la conception rigoureuse de systèmes et, indirectement, sur des statistiques robustes pour mesurer la vigueur de la production et pour appliquer cette mesure à certains cas intéressants.
\end{abstract}

Mots clés : Entropie, redondance, conception rigoureuse

While the efficiency of economic arrangements is the primary focus of economic research, we may ask whether the efficiency improvements that have been experienced in the developed economies have been accompanied by increased vulnerability of output to catastrophic events. In order to address this question usefully, we need some implementable measures of vulnerability of output to disruptive events or large shocks. This study attempts to provide some rudimentary measures of this potential increased vulnerability in economic systems. To do so we draw on concepts from information theory, robust system design and, indirectly, robust statistics to define a measure of the robustness of production, and apply the measure to some cases of interest.

Keywords: Entropy, redundancy, robust design

\footnotetext{
* I thank the Fonds québécois de la recherche sur la société et la culture (FQRSC), the Social Sciences and Humanities Research Council of Canada (SSHRC) and CIRANO (Centre Interuniversitaire de recherche en analyse des organisations) for support for this research. I am grateful to Jim Engle-Warnick and Leah Brooks for very helpful discussions and comments. Preliminary and incomplete version.

${ }^{\dagger}$ John W. Galbraith, Department of Economics, McGill University, 855 Sherbrooke St. West, Montreal, Quebec H3A 2T7, Canada. Email: John.Galbraith@ cirano.qc.ca.
} 


\section{Introduction}

The efficiency of economic arrangements is the primary focus of economic research. This focus properly reflects the potential for improvements in the efficiency of production and the gains that have in fact been realized, over long historical periods, in the productivity and aggregate output of the economy.

Nevertheless, it is reasonable to ask whether the productivity, or efficiency, improvements that have been experienced in the developed economies have been accompanied by changes in the vulnerability of output to catastrophic events. Consider for example a manufacturing facility with a marginal cost of production which is always declining in the quantity produced, i.e. a natural monopoly. If the costs of distribution are small, the most efficient arrangement will entail concentration of all production at a single location. As long as the probability of a disruption at this location is sufficiently small, this efficient arrangement is also optimal in a broader sense. By contrast, if there is a substantial probability of disruption at any given location, this efficient arrangement may be less robust to catastrophe than production at multiple points.

To take another example, consider the water supplies of a set of scattered houses. If each householder has his or her own supply of water, each must maintain a separate system of well, pump, etc. If the householders form a village and centralize water supply, the single system potentially reduces expense and effort in maintenance very substantially: that is, there is a potential increase in efficiency. However, the single system now makes this set of householders more vulnerable to serious disruption; equipment failure or contamination could eliminate water supply for all, whereas with separate systems neighbours could supply each other in the event of a failure of one of the individual systems. Raising efficiency under some typical or ideal circumstances may have a cost in increased vulnerability under less favourable circumstances.

The study of the vulnerability of output to disruptive events, or conversely the robustness of economic arrangements, has a parallel in the statistical literature: the most efficient estimator of a population parameter is not in general the most robust, and vice versa. It may be sensible to sacrifice some degree of efficiency in ideal cases in return for a more robust estimator which will perform better under some adverse circumstances, and it is possible that the same may be true of structures or elements of organization underlying economic activity.

The efficiency gains realized in developed economies depend to a degree on crucial infrastructure such as electricity and fresh water supply. These important structural elements underlying economic activity may be affected by destructive events such as extreme weather, terrorist activity, earthquakes and fires; there have been a number of examples in which economic activity at the level of a city has been severely disrupted by such events. ${ }^{1}$ If we can measure the robustness of these crucial infrastructure elements, then we will have some information about robustness in the broader economy that depends on them. This is the approach taken in the present study: although we cannot measure all elements relevant to robustness of economic activity, we can characterize the robustness of systems whose failure has been responsible for major economic disruptions in the past.

\footnotetext{
${ }^{1}$ Examples include Hurricane Katrina (New Orleans), the August 2003 electrical blackout (northern New York state, Toronto), and the 1998 ice storm (Montreal).
} 
Since we do not have official statistics measuring vulnerability to parallel those measuring economic output, it is difficult to evaluate the position of a particular economy, any changes that may have taken place over time, or the impacts of changes that could be implemented to reduce vulnerability. This study attempts to provide some such measures of the vulnerability of these structural elements in economic systems. To do so we draw on concepts from information theory and robust system design to define measures of the robustness of the supply of crucial elements underlying economic activity, and apply the measures to some cases of interest, at the level of particular cities. The next section provides some background information on robust system design, and the measurement of reliability in engineering systems. We then consider some examples to illustrate problems of interest in the context of economic infrastructure. Following the examples, we define some properties which we may consider necessary in the context of numerical measures of robustness, and consider several candidate measures which could be applied in economic contexts.

\section{Background concepts and definitions}

\subsection{Robustness}

When a destructive event arises in part of a system, there are a number of features of the system which will tend to reduce the impact of the event. The impact will tend to be lower where:

- another part of the system can directly replace the output of the part affected by the destructive event

- the destructive effect can be localized to the part of the system where the event arose (error propagation is limited)

- another part of the system can be adapted to replace all or part of the lost output

- the affected part of the system can be repaired quickly

In order to provide some corresponding operational measures we will begin with some formal definitions of terms, which will be closely related to those which have been used in other contexts. In particular, there are substantial literatures in engineering and biology on system robustness, redundancy or degeneracy; see for example Sussman (2007), Tononi et al. (1999), Edelman and Gally (2001). Robust machines or systems are described as those that tolerate faults (e.g. Schuster 2008), provide low performance variation when conditions change (e.g. Gaury and Kleijnen 1998), or are designed to be insensitive to variation in conditions. The idea of design to reduce performance sensitivity to variation in conditions, rather than attempting to eliminate variation in conditions, is often associated with Taguchi; see for example Taguchi (1986).

The definition of robustness that we use is based on statistical concepts that date at least to Box and Andersen (1955) and Tukey (1960); the definitions of redundancy and adaptability are based on those given by Tononi et al. (1999), who use the term 'degeneracy' rather than 'adaptability'. Entropy is used as a measure of information content by Shannon (1948). 
Definition 2.1 Robustness. One system is more robust than another if it performs relatively well when conditions differ from the ideal.

Definition 2.2 Redundancy. A system contains redundant features if some elements duplicate the function of other structurally identical elements.

Definition 2.3 Adaptability (degeneracy). A system contains adaptable features if the functions of some elements of the system can be performed by other structurally different elements.

Note that in a system containing redundancies, some elements can be made inoperative without negatively affecting performance of the system; in a system with adaptable features, adaptation to inoperative elements may entail some sacrifice in performance.

Definition 2.4 Entropy. Let $i=1,2, \ldots N$ index elements of a set $\Omega_{N}$ which can be aggregated to a total value $\omega=\sum_{i=1}^{N} \omega_{i}$. Then the entropy of the set $\Omega_{N}$ is

$$
\rho\left(\Omega_{N}\right)=-\sum_{i \in \Omega_{N}} \frac{\omega_{i}}{\omega} \ln \left(\frac{\omega_{i}}{\omega}\right) .
$$

A set with high entropy is one for which the aggregated value is highly dispersed among the individual elements.

\subsection{Reliability}

A related set of definitions is made in engineering literatures concerned with reliability. Here 'reliability' corresponds with a probability, and an overall probability computation is carried out conditional on probabilities of failure of components of a system, which are assumed to be estimable. It is useful to contrast the failure probabilities of serial, parallel and $n$-modular redundant systems.

Definition 2.5 Failure and reliability. A system is said to fail when it no longer provides a specified level of performance. The reliability of a system, for a given period of time, is the probability that there will be no failure over the period, or 1 - the probability of failure.

Definition 2.6 Serial system. A serial system is one in which an input passes through each one of a number of components in sequence, such that each one must be functioning for the system to function.

Definition 2.7 Parallel system. A parallel system is one in which an input may pass through any one of a number of components, such that only one of the components needs to be functioning for the system to function.

These are relatively stylized definitions; more elaborate cases can of course also be considered. 
Let $R$ denote the reliability of a system and let $r_{i}, i=1,2, \ldots N$ denote the reliability of each of the $N$ components of the system; we suppress a further subscript indicating the period of time considered. For a serial system with independent component failure probabilities,

$$
R=\prod_{i=1}^{N} r_{i}
$$

for a parallel system with independent component failure probabilities

$$
R=1-\prod_{i=1}^{N}\left(1-r_{i}\right)
$$

Systems can often be characterized as combinations of serial and parallel elements; overall failure probabilities and reliability can be computed from the reliabilities of the serial or parallel components.

The following definition is adapted from the more usual definition of $N$-version modular redundancy. ${ }^{2}$

Definition 2.8 N, $m$ Modular Redundancy. An $N, m$ modular redundant system is one consisting of $N$ independent modules operating in parallel, and where at least $m$ of the modules must be functioning for the system to function.

The reliability of an $N, m$ modular redundant system can be computed as the probability that at least $m$ of the modules will not fail; with modules having equal and independent reliabilities $r$,

$$
R_{N, m}=\sum_{i=0}^{N-m} C(N, i) r^{N-i}(1-r)^{i},
$$

where $C(N, m)=\frac{N !}{(N-i) ! i !}$ is the combinatorial operator. That is, we compute the probabilities of $0,1, \ldots N-m$ modules remaining reliable, and add the probabilities of these reliable states; if more than $N-m$ modules fail, the system fails. Note that this definition is a generalization of the simple parallel system defined in D2.7, for which $m=1$, and that $R_{N, 1}=\sum_{i=0}^{N-1} C(N, i) r^{N-i}(1-r)^{i}=1-\prod_{i=1}^{N}\left(1-r_{i}\right)$.

While estimating reliability is valuable in the context of a physical structure such as an electricity grid, there are several reasons why this may be insufficient to characterize

\footnotetext{
${ }^{2}$ In the standard definition of $N$-version modular redundancy, there is an additional stage in which a voting or arbitration mechanism decides on a correct value when information provided by the modules differs. For example, a chemical process may be monitored with three temperature indicators. Where these indicators do not agree, a further mechanism decides which module(s) to treat as being correct.
} 
vulnerability of economic systems, even where we use the vulnerability of the physical structures to characterize vulnerability of the economic systems depending on them. First, actual failure probabilities may be difficult to characterize; the probability of an earthquake, for example, is very hard to estimate in some geographical regions. Second, some destructive events of the type that interest us may not be well characterized by probability distributions, because they may be the result of deliberately planned acts of sabotage. We would expect such acts to be directed at the most vulnerable points in a system. As well, the probability of failure of a system is only one quantity which we want to discover; we are also interested in the degree of functionality that remains following some component failures: that is, we are also interested in performance conditional on a serious destructive event having taken place.

The next section provides a few preliminary examples intended to be descriptive of important elements of economic infrastructure underlying general economic activity.

\section{Examples of system structures}

The examples of structures in this section are given as background to subsequent discussion of numerical measures of system robustness, in order to illustrate some cases that need to be distinguished by the measures.

Figure 1 provides a number of examples of structures of supply. The required output (e.g. electricity, potable water, fresh food) is produced in the boxes and is moved downward along lines to consumers at the bottom. Each box may be taken to produce the same quantity. We will define 'sources of supply' formally in the next section, but for purposes of these examples, the sources of supply will be the most vulnerable points in the link between production sites (top of diagram) and the end user (bottom of diagram). Here, although production occurs in the boxes, these are not in general the sources of supply in the relevant sense; instead the sources of supply are the points through which most output passes (bottlenecks). In the examples $\left(A, A^{\prime}, B, C, C^{\prime}, D\right)$ given graphically, the numbers of sources of supply are respectively $(1,1,4,2,2,2)$. The different structures show differing degrees of robustness to destructive events.

These examples contain both serial and parallel elements, if we consider the transmission paths as components of the system. With information about the failure probabilities of the various elements, we could compute reliability measures for these systems. However, our interest in this study will be in performance of the system conditional on a some destructive event having taken place. We will therefore consider these systems with respect to the degree of loss of performance after one or more failures of crucial components.

Cases $A$ and $A^{\prime}$ differ in the number of production sites, but each has the property that all output passes at some point through a single transmission channel. They are therefore equivalent with respect to robustness: a single destructive event can eliminate all supply. We might therefore calibrate a measure to assign a value of zero for the robustness of these structures, and the measures that we will consider will do this.

Case $B$ is more robust in that the worst that a single destructive event can do is to eliminate one of the four sources of supply. A numerical measure should therefore assign $B$ a higher robustness value than $A$. Note however that $B$ 's sources cannot substitute for one another; outputs from one source can only flow to end users connected to that source. 
We will return to this point in comparing cases $C$ and $D$.

Case $C$ has two sources of supply, and the end users supplied by each are again separated, so this structure appears less robust than $B$ but more robust than $A$. In each of $B$ and $C$, there are four sites at which production is carried out (the four boxes), but $C$ 's production sites are paired in passing through a single source, making the structure less robust. Two destructive events can end all output in case $C$. Case $C^{\prime}$ is similar in structure to $C$, but with two unequal sources: the source on the right groups two production sites, and that on the left three production sites (again, each of these produce the same quantity in these examples). The worst destructive event in case $C^{\prime}$ will then eliminate a greater quantity of supply to the end users (who are not connected across sources) than will the worst destructive event for case $C$, so we might assign $C^{\prime}$ a lower measure of robustness.

Finally, case $D$ resembles $C$ in having two sources (each of which consolidates two production sites). However, in case $D$ each source can supply any end user. If the supply is just sufficient to meet requirements, then we might deem $D$ and $C$ to be equally robust, in that the worst destructive event will eliminate half of supply, and another could eliminate all. But if the sources of supply can each produce more than $50 \%$ of the requirement, then $D$ might be said to be more robust: the worst destructive event can eliminate either source, but the remaining source can supply more than $50 \%$ of the end users with the required output. If for example each source has enough spare capacity to meet all required output, then one source can be destroyed with no loss in output to end users.

Measures of robustness will have to address each of these points: the number of sources defined as the minimal set of conduits through which all production passes, their total capacity relative to requirement, and their ability to substitute for one another by having access to all end users.

In the next section we will define some formal requirements for numerical measures of robustness and introduce measures which meet these requirements and capture the features just noted in the graphical illustrations.

\section{Measures of system robustness}

We now need to integrate these various features of a robust system into a measure suitable for application to a substantial aggregate economic system, at the level of a city or a larger economic unit. The measures that we will consider will give use information about robustness and redundancy; adaptability will in general be more difficult to observe.

Different possible measures will indicate robustness to different types of possible disruption. For example, we might attempt to measure robustness purely to a single event at the system's most vulnerable point; we might think of this as a measure of the most damage that can be done by a planned attack on one element of the system. Of course, the economy of a city can be completely destroyed by a sufficiently large destructive event, as has often happened during wars; in measuring robustness we attempt to characterize performance of a system in response to relatively small deviations from ideal conditions. However, an ideal measure would indicate a continuum of degrees of vulnerability to events of differing magnitude.

In discussing these measures, we need to define what we mean by a source of supply. 
Definition 4.0 Source of supply. Let $N$ be the smallest number of sites than need be destroyed in order to stop all supply, and let $\omega_{1}, \omega_{2}, \ldots, \omega_{N}$ be the corresponding minimal set of sites. Then $\omega_{1}, \omega_{2}, \ldots, \omega_{N}$ are the sources of supply.

Note that this definition makes the sources of supply the 'bottlenecks' in supplying end users, not necessarily the sites at which actual production takes place; the source of supply may be part of the system of transmission or distribution rather than production. Two production sources that are not independent, in the sense that they pass through a single transmission point, are one source of supply in the sense of definition 4.0. For example, consider electric power produced at several sites such as hydroelectric dams, and transmitted to a city via a single transmission line. Then by definition 4.0, the transmission line, rather than the dams, is the relevant source of supply.

This definition is aimed uncovering robustness to catastrophic events or to deliberate destruction, where we want to examine the consequences of the most serious events that could arise. In the probabilistic reliability model, we assume that we can characterize failure probabilities for serial and parallel components to compute overall reliability; by contrast, using definition 4.0 and the following measures, we examine robustness to destructive events arising at the most vulnerable points. The two classes of measures reveal different information about potential system failure.

\subsection{Properties of measures}

We will only consider measures that fulfill a few simple conditions. Let $M$ be any measure of system robustness which is consistent with the properties given below.

i (monotonicity) If an additional source of supply $x_{N+1}$, is added to the system, then $M$ does not decrease.

ii (dispersion) If additional supply in quantity $\mathrm{Z}$ is added to the system, (a) as one source, $x_{N+1}=Z$, or (b) as multiple sources $\sum_{i=1}^{k} x_{N+i}=Z$, then $M$ increases at least as much in case (b) as in (a).

iii (minimal robustness) If there is only one independent source of supply (i.e. if all output can be lost through destruction at one point), then $M \equiv 0$.

iv (dominance) If two systems $\mathrm{A}$ and $\mathrm{B}$ have the same structure, but each source of supply in $\mathrm{A}$ is at least as great as the corresponding source of supply in $\mathrm{B}$, and one source of supply in A is strictly greater than the corresponding source in $\mathrm{B}$, then $M_{A} \geq M_{B}$.

$\mathrm{v}$ (scale invariance) If the outputs of all sources, and the total requirement $R$, are changed in the same proportion within the same structure, then $M$ is unchanged. 


\subsection{Measures of robustness}

Let $x_{i}, i=1, \ldots, N$, with $x_{i}>0 \forall i$, index sources as defined above, let $X=\sum_{i=1}^{N} x_{i}$ be the total supply available, and let $R$ be total required supply. ${ }^{3}$

A first measure to consider, because it commonly used in analogous contexts to measure dispersion, is the simple entropy, in this case of the sources of supply. This does not require any knowledge of what total required supply is; it uses only the total supply available.

Definition 4.0 Measure 0 (entropy of sources). $m_{0}=-\sum_{i=1}^{n}\left(\frac{x_{i}}{X}\right) \ln \left(\frac{x_{i}}{X}\right)$.

Although $m_{0}$ measures dispersion, and is therefore related to the limitation of error propagation, it takes no account of any excess capacity, or redundancy, in the system. Relatedly, entropy will fail the monotonicity (i) and dominance (iv) properties; it does not reflect the absolute level of output. Outputs from three sources of 50, 50 and 50 will give a higher entropy measure than outputs from three sources of 80, 70 and 60 in the same structure and with the same required supply.

An entropy measure is therefore not fully satisfactory for our purposes. An alternative is to adapt the simple entropy measure $m_{1}$ via a non-negative re-scaling that takes into account redundancy (implying that $X>R$ ). We do this with measure 1 ; if there is no redundancy $(X=R)$, measures 0 and 1 are equal.

Definition 4.1 Measure 1 (re-scaled entropy of sources). $m_{1}=m_{0}\left(\frac{X}{R}\right)$.

Measure 1, unlike 0, can be shown to fulfill each of the conditions i - iv above. This re-scaled entropy measure may perform well, as we will see in further examples below. However, measure 1 does not capture the distinction between cases $\mathrm{C}$ and $\mathrm{D}$ given above; the fact that the supply system for some end users is cut off from that of others, limiting adaptability of the system, is not reflected in measure 1 . For cases such as D where this does not arise, as in typical city-level electrical grids or water distribution networks, measure 1 may be sufficient. In other cases, we can define a further measure which capture this effect, but which imposes higher informational requirements in order that they be calculable.

Measure 2 is an example. It is based on the sum of the proportions of required capacity that remain after a sequence of destructive events. To define it, we need to define further measurements of properties of the structure.

Let source 1 be that which, if destroyed, would lead to the largest single loss of output to end users, and let $\ell_{1}$ be the loss of supply that arises if source 1 is destroyed. Note that, in a system with redundant capacity, $\ell_{1}$ may be zero, because source 1 can be fully replaced. In the case where the actual loss of output from any one source is zero, we will choose as source 1 that for which the output $x_{i}$ is greatest.

Next let source 2 be that which, if destroyed, would lead to the largest loss of output to end users given that source 1 has also been destroyed. Let $\ell_{2}$ be the cumulative loss of

\footnotetext{
${ }^{3}$ Where there are a number of separate end-users who must be supplied, for example domestic electricity consumers, then we may interpret $q_{i}$ as the proportion of end users who receive the required supply.
} 
output divided by the required output $R$ when both 1 and 2 are destroyed. Similarly, source $k$ and $\ell_{k}$ are respectively the $k$ th most important source in this sense and the cumulative loss of output from elimination of all sources up to $k$ inclusive, as a proportion of the total required $R$. Since the losses are proportionate, we have $\ell_{i} \in[0,1] \forall i$ and $\ell_{N}=1$ where there are $N$ sources of supply.

The next measure sums the remaining supplies after a sequence of events up to $N$; higher values indicate that more capacity remains after a limited sequence of destructive events, implying greater robustness.

Definition 4.2 Measure 2. $m_{2}=\left(\frac{X}{R}\right) \sum_{i=1}^{n}\left(1-\ell_{i}\right)$.

Measure 2 requires more information than measure 1, since we need to know the cumulative output losses, entailing information about the distribution network 'downstream' of the sources. However, if this information is available, it will allow us a more subtle measure in cases where the distribution network is incompletely connected. Scaling by $X / R$, as with measure 1, allows some effect in the measure of a large output from source 1, which would otherwise have no effect since source 1 is eliminated in computing each term in the summation.

As an example, consider a case where there are three sources of supply, which respectively produce $60 \%, 30 \%$ and $10 \%$ of the required supply. In this case there is no redundant capacity and $X=R$. Then $\ell_{1}=0.6, \ell_{2}=0.9, \ell_{3}=1$; correspondingly, the cumulative effects of the loss of sources 1, 2 and 3 in that order are such that remaining capacity after each loss is $40 \%, 10 \%$ and 0 ; measure 2 takes the value $0.4+0.1=0.5$. If we modify this example to show excess capacity, for example because the sources produce instead $70 \%$, $45 \%$ and $20 \%$ of the requirement, then $m_{2}$ is higher: in this case loss of the first source leaves $65 \%$ of required supply, and subsequent loss of the second leaves $20 \%$ of required supply, so that $m_{2}$ becomes $0.65+0.2=0.85$.

Table 1 records the values of these measures for the examples given graphically in Figure 1. The values of measures 1 and 2 will depend upon whether there is supply available beyond the requirement $(X>R)$ or not, and the table records cases with $X=R$ and with $X=1.5 R$; the pure entropy measure 0 does not depend on $R$, and so appears only once in the table.

All measures assign values of zero to cases $A$ and $A^{\prime}$, as desired. All measures show $B$ as the most robust case. Where $X=R$, all measures show $C$ and $D$ as equally robust; the ability in $D$ to transfer output to any end user is of no value when there is no extra output to transfer, so loss of $50 \%$ of supply causes the same effect as in $C$. Case $C^{\prime}$ is slightly less robust by each measure, since the worst destructive event can remove slightly more than $50 \%$ of capacity (there are 10 end users on the right-hand side of $C^{\prime}$, and 7 on the left, so the worst single event leaves 10/17 without supplies).

Where $X=1.5 R$, the raw entropy is unchanged and is not recorded again. The re-scaled entropy is higher; the extra capacity is reflected in higher measured robustness. However, the ranking of cases is unchanged here, since only the ratio of $X$ to $R$ is used, and the ability in case $D$ to transfer output from either source to any end user is not reflected in the measure. Measure 2 does use this information, and promotes case $D$ to a higher 
robustness ranking than $C$ or $C^{\prime}$. Case $B$, in which some output remains after even three destructive events, remains the most highly ranked for robustness.

\section{Measures applied to urban economies}

[not yet available] 


\section{REFERENCES}

Box, G.E.P. and S.L. Andersen (1955) Permutation Theory in the Derivation of Robust Criteria and the Study of Departures from Assumption. Journal of the Royal Statistical Society Ser. B 17, 1-34.

Edelman, G.M. and J.A. Gally (2001) Degeneracy and Complexity in Biological Systems. Proceedings of the National Academy of Sciences USA

Gaury, E.G.A. and J.P.C. Kleijnen (1998) Risk Analysis of Robust System Design. Proceedings of the 1998 Winter Simulation conference, Medeiros et al., eds.

Schuster, A. (2008) Robust Artificial Neural Network Architectures. International Journal of Computational Intelligence 4, 88-94

Shannon, C.E. (1948) The Mathematical Theory of Communication. Bell System Technical Journal; reprinted in Shannon, C.E. and W. Weaver, (1949), The Mathematical Theory of Communication. Urbana, Illinois, University of Illinois.

Sussman, G.J. (2007) Building Robust Systems: an essay. Working paper, MIT.

Taguchi, G. (1986) Introduction to Quality Engineering: Designing Quality into Products and Processes. Kraus, White Plains, NY.

Theil, H. (1967) Economics and Information Theory. North-Holland, Amsterdam.

Tononi, G., O. Sporns and G.M. Edelman (1999) Measures of Degeneracy and Redundancy in Biological Networks. Proceedings of the National Academy of Sciences USA 96, 32573262 .

Tukey, J.W. (1960) A survey of sampling from contaminated distributions. In Contributions to Probability and Statistics, I. Olkin et al., eds., Stanford University Press. 
Figure 1

Examples of system structures

A)

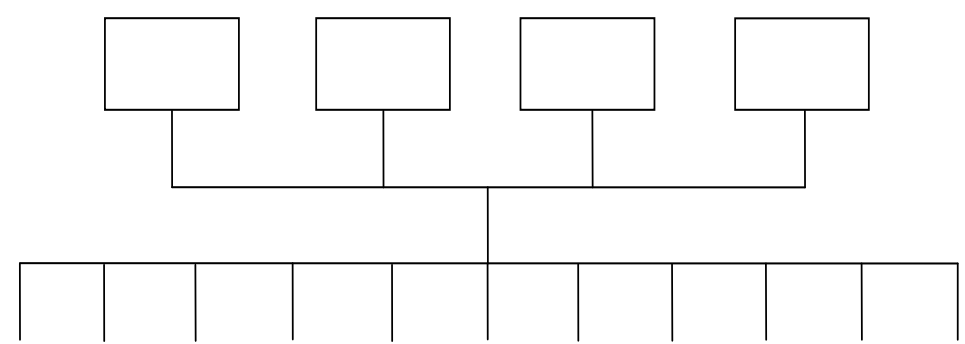

$\left.A^{\prime}\right)$

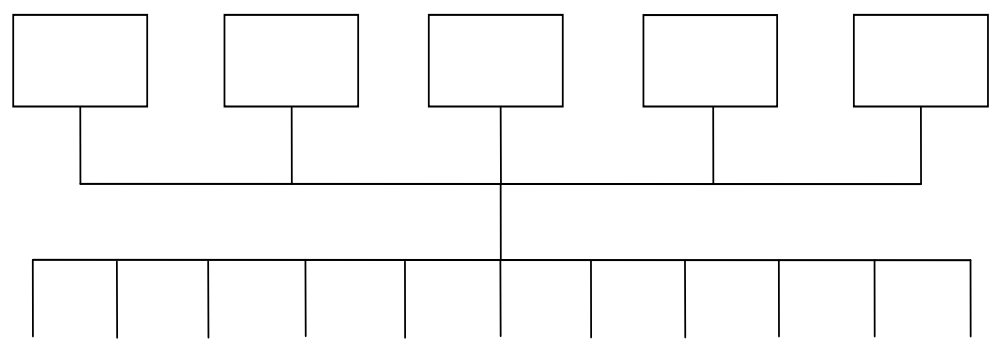

B)

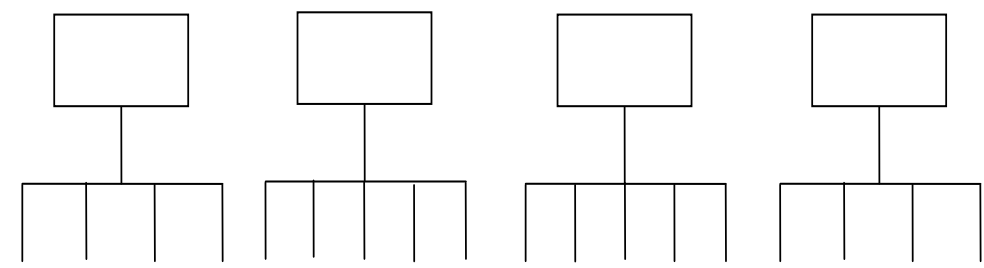


Figure 1, CONTINUED

Examples of system structures

C)

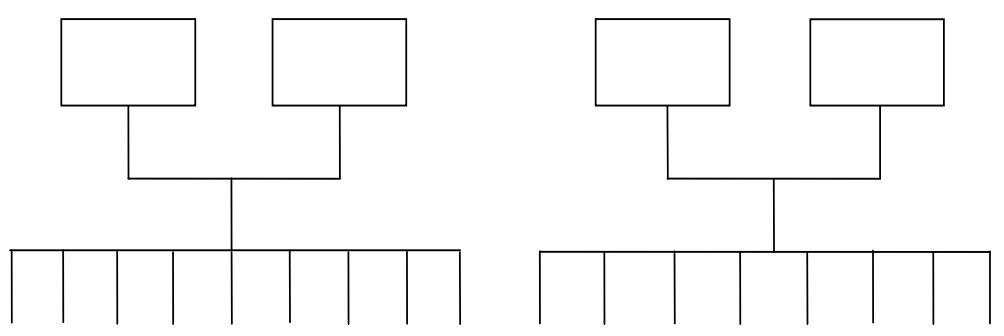

$\left.C^{\prime}\right)$

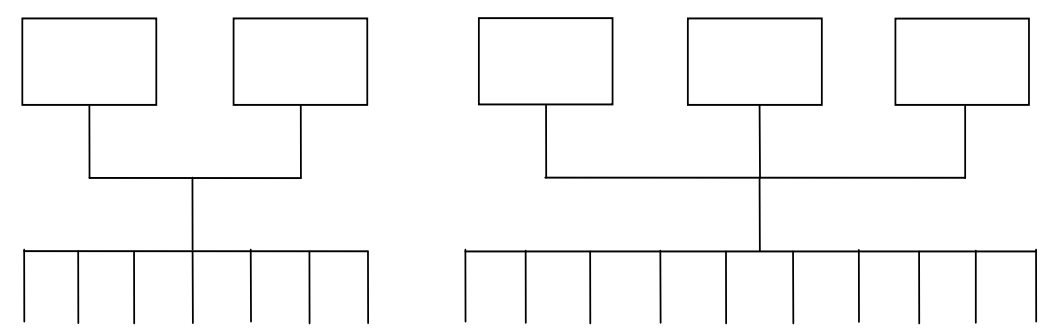

D)

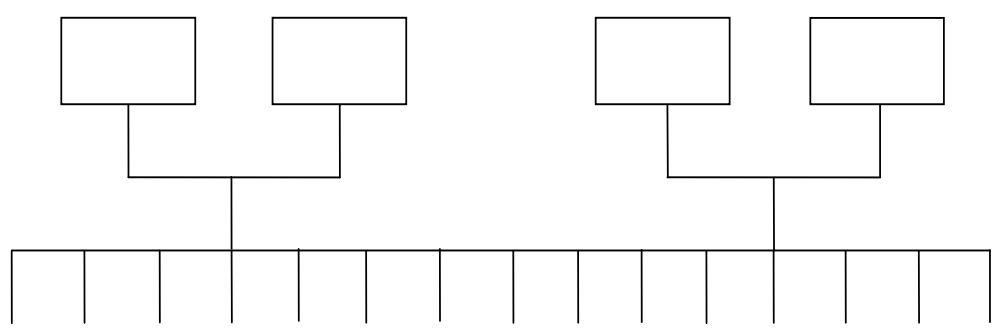


TABLE 1

Values of measures $m_{0}-m_{2}$ in example cases

\begin{tabular}{lccccc}
\hline & \multicolumn{5}{c}{ Measure: } \\
& $m_{0}$ & $m_{1}$ & $m_{2}$ & $m_{1}$ & $m_{2}$ \\
& $X=R$ & $X=R$ & $X=R$ & $X=1.5 R$ & $X=1.5 R$ \\
Example: & & & & & \\
$A$ & 0 & 0 & 0 & 0 & 0 \\
$A^{\prime}$ & 0 & 0 & 0 & 0 & 0 \\
$B$ & 1.386 & 1.386 & 1.5 & 2.079 & 2.25 \\
$C$ & 0.693 & 0.693 & 0.5 & 1.040 & 0.75 \\
$C^{\prime}$ & 0.677 & 0.677 & 0.412 & 1.016 & 0.618 \\
$D$ & 0.693 & 0.693 & 0.5 & 1.040 & 1.125 \\
& & & & & \\
\hline
\end{tabular}

